\title{
Research on Home Consciousness in Japanese Language and
}

\author{
Literature \\ Yuyang Shan ${ }^{1, a}$ \\ ${ }^{1}$ College of Foreign Languages, Bohai University, Jinzhou, Liaoning, China, 121013 \\ ${ }^{a}$ email
}

Keywords: Japanese Language, Japanese Literature, Home Consciousness

\begin{abstract}
As China's neighbor, Japan has many similar places with Chinese in the language and culture field. In recent years, as the international exchanges have become increasingly close, Chinese scholars have studied the Japanese culture and language deeply. This paper firstly discusses the general situation of Japanese language and literature, then analyzes the basic connotation of home consciousness in Japanese literature, and finally gives the relevant implications of the home consciousness to provide some references for the relative researchers.
\end{abstract}

\section{Introduction to Japanese Language and Literature}

China and Japan are friendly neighbors across the sea. The culture of the two countries has a deep foundation and broad common ground. Japanese culture has been influenced by the Chinese history and culture, so as to keep a lot of Chinese history and traditional culture in the inherent mark. However, with the development of the Meiji Restoration in Japan, the Japanese culture began to be influenced by western thoughts, so it has obvious characteristics of western culture. In a certain period of time, Japan still has its own culture and the Western cultural exchange collision phenomenon, the final integration of the two forms of the Japanese advanced social mainstream culture. Through the research of the art characteristic and the law of development of Japanese language and literature, we can see the development and evolution of Japanese domestic mainstream ideology, and to improve the study of Japanese language and literature in China to the theory system.

Japanese language and literature in many aspects have been affected by the Chinese traditional culture, so with the distinctive characteristics of Chinese traditional culture and the inherent mark. Japan since the Meiji has started to break the situation of seclusion, western culture began to pour into Japan, has brought a major impact on the development of Japanese language and literature. Although Japan has a lot in common with China, but the Japanese pronunciation and spelling rules and Chinese have the essence of the difference, so Japanese language and literature with a distinctive mark. The process of Japanese language and literature development history is not simple but a new culture. Whether it is the early Japanese works or the modern works of Japan, have shown a strong social nature in literature, which is a major feature of Japanese language and literature. Japan's modern literary works will focus on the development of the social status of each stage of the history of Japan, and the expression of longing for the future and longing. Due to the impact of the Japanese region, the Japanese literary works are closely related to the changes of the times. Japanese literary works have appeared the tendency of urbanization, which is the background 
of economy, politics and culture. Until Japan entered the Edo period, the Japanese samurai began to become the new aristocracy. Some people engaged in literary creation in the samurai led to the transfer of domestic literature center.

\section{Basic Connotation of Home Consciousness in Japanese Language and Literature}

Home in Geographical Sense. No home can be a real dilemma. Therefore, each individual want a home of his own. The dilapidated farmhouse damaged fence, abandoned land, away forests and frequent natural disasters, atmospheric pollution and the population continued to increase regional war constantly without show living difficulties caused generation survival crisis and the loss of their homes. To get rid of this dilemma, we should first build and rebuild the sense of modern home, find the origin of the existence of the land, stick to and return to land, and then establish a sense of home, the recovery and re-establishment of the meaning of existence. Secondly, on the basis of modern home consciousness, change the material of excessive demand to society caused by the ecological crisis or disaster, the possibility of re-establishment of a dwelling, in order to achieve the reality of the ideal home ownership. Nara period is the forming period of the concept of Japanese literature, the main works and Chinese literary form has many similarities, mainly by the time of its creation is then spread more widely in folk culture form. Concise text, language easy to understand and easy to sing, and provides a theoretical basis for the future development of Japanese literature. Urban culture, both in terms of material and spirit, shows the characteristics of urban culture, which is different from the agricultural civilization of the ancient village in Japan. The material culture of the city reflects the improvement of people's living standard. These descriptions and discussion deeply show us the people's homes ideology and the survival crisis they faced in the different social backgrounds. How to understand and solve these home consciousness and survival crisis to us today's human inspiration and challenge is our modern earth people are faced with an important common subject.

Home in Spiritual Sense. The modern home consciousness not only means that people realize the significance of home geography. It also enables people to realize their freedom to survive, to obtain a sense of care and recognition of the spiritual layer of the invisible home, that is, the spiritual sense of the modern home. This awareness is the reflection of the past, on the present understanding and future of the construction of spiritual knowledge, it is the culture system by a variety of elements that constitute the organic cultural identity, values, emotions, ideals and beliefs. Therefore, the spiritual sense of the construction and reconstruction of the modern sense of the home should be paid equal attention. First of all, to nurture and formed by reform and innovation as the core of the great spirit of the times, overcome the supremacy of the ecological balance, adhere to the natural transformation of the concept; secondly, rooted in the cultural inheritance, cultural integration, to avoid the disasters of the war, the building of a harmonious world, to achieve self by equality, democracy and rule of law fairness and justice in the spirit of the world. Construction and remodeling in the changes of modern people in the world living dilemma or crisis and realize the modern dwelling ideal and has very important significance of modern home consciousness. The spirit of the city culture, and also the people in the city of this particular living space created by the people themselves and in turn has a huge impact on people's lives, the spirit of the city culture that the city itself shows the characteristics of a kind of different from the traditional culture. In Japanese literary works, the strong sense of home and the crisis of life which are revealed by the host and the strong sense of life have given us a unique angle of view. It was warning and alerts us, when we are in the different sense of home straight and survival dilemma or crisis and find the 
dwelling place inside when the driving force and strong will. A sense of home will create a home, which make you not fear the survival dilemma or crisis.

\section{Implications of Home Consciousness in Japanese Language and Literature}

Home is the Recognition of Identity. Any person needs identification in his life. Who am I? Where do I come from? These problems are the basic problems that people need to face. Home gives the answer to the questions. You are the person from your hometown. In this regard, the Japanese literature pointed out that the identity of the identity of the home. Identity is a kind of cognition and description of the subject itself, including many aspects such as cultural identity and national identity. Because of the different cultural subjects, it needs the identity of the main body, and the interaction between the main body of culture leads to the evolution of the identity. Identity is mainly the problem of cultural identity, mainly by the main body of the individual attributes, historical and cultural and development prospects. Identity degree is the representations of the identity among individuals in many cultures. This word is now mainly in the aspects of philosophy, literature, anthropology, sociology, film and so on. In the construction field, in addition to the architect as a cultural individual to discuss, while the building is rarely cited. From a cultural point of view, in the process of individual identity, the power of the cultural institutions to promote the individual to participate in cultural activities actively or negatively, in order to achieve their identity. Collective identity refers to the cultural main body in two different cultural groups or sub groups to choose between. Because of the influence of different cultures, the subject of culture should be regarded as the self of the collective culture, and the other culture as the other. Social identity, emphasizing the social attributes of people. One of the most typical is the sorrow of parting poems and homesick poetry. These poems have shown a poet in his hometown nostalgia. In addition, under the influence of the war, the Japanese language and literature also showed the poet's love for the destruction of the home.

Home is the Symbol of Peace. Homeland consciousness is regarded as a symbol of peace in Japanese language and literature. Whether the traditional Japanese language and literature characteristics and forms, or in modern Japanese language and literature characteristics and forms, there are a lot of Japanese language work this meaning in the performance of peace in the process of creation. Here refers to the "peace" not only refers to people living in harmony and peace, but also symbolizes the people's heart of a kind of quiet feeling. From the evolution of Japanese literature history, we can see that the Japanese literature has experienced a long development process. The impact of seclusion policy and the people's traditional thoughts in the process of development, the development process is not smooth. But after a period of development, the Japanese finally get rid of the shackles of "Seclusion", the farming culture has been hitherto unknown impact of Japan's economic form has changed. The Japanese language and literature in peace is brought about by the Japanese legacy of farming culture, but when the peace was damaged by the war, Japan also bring disaster to the other countries in the country at the same time, so that the people of his country in the war against, the influence of social reality people under the tranquil mood rising, and this phenomenon can be reflected in the literature of this period in. After the Second World War, Japanese literature creation still with a strong home tragedy color, this is the war to bring people the trauma. In this period, there are many female writers, in their works through the delicate description, will lose their homes and loved ones suffering performance out.

Home is the Miniaturization of State. In Japanese literature, a typical characteristic of consciousness is embodied in many literary works. Literature in the process of creation, love will be a big idea and cognitive narrowing, narrowed by a larger range to a small extent, and in the process 
of writing, to see a small expression, to express their social perception and comprehension. This expression can truly reflect the Japanese people's life. The Japanese people are longing for life, such as living environment, the courtyard layout, food culture and so on through the narrow display in front of the reader. For Japanese writers, they are in the process of writing, it will be reduced to the family, and through the description of the family to reflect the strong family and the Japanese people aspire to the way of life. However, there are many modern writers, they are in the process of writing, the courtyard as a description of the key, and the writer's literary works should not only reflect the design ideas and the overall layout of the courtyard, also should reflect the Japanese people's life view and cultural view. In this period, Japan also appeared a lot of female writer and essayist, its performance is more prominent, provides a good foundation for the development of Japanese fiction, promote Japanese fiction and vigorous development of these female writers' works are beautiful and dignified style, fully demonstrated the feminine characteristics and is more sensitive to things. Japan is a very family oriented country. The Japanese will be the family's sense of identity as their beliefs. In their view, the family is not only to maintain emotional ties, or to maintain social harmony and stability; only into the family, can only rely on the material and spiritual aspects; and once left the family, it means the loss of the root, did not rely on. In many Japanese literary works. In the Japanese language in literary works, created many of the courtyard, the courtyard is not simply write the overall layout. The writer wrote this meaning in a small courtyard, reflecting fact that home is the minimization of state.

\section{Conclusion}

Home consciousness is the most important subject in the creation of Japanese language and literature. In the process of writing, writers not only show the deep feelings of their loved home, but also show the people's vision for better lives. Chinese scholars can start the research from home consciousness in the Japanese language and literature research to improve the Japanese language and literature research system.

\section{References}

[1] Xue Yihe, Literature Education, Vol. 12 (2016) No 1, p.47

[2] Xu Wenna, Industrial \& Science Tribune, Vol. 15 (2016) No 11, p.134-135

[3] Luo Zizhou, The Fortune Times, Vol.32 (2016) No 4, p.429

[4] Wang Zhenghong, Time Education, Vol.10 (2013) No 17, p.131 